\title{
Spectroscopy and energy level location of the trivalent lanthanides in $\mathrm{LiYP}_{4} \mathrm{O}_{12}$
}

\author{
P. Dorenbos ${ }^{1}$, T. Shalapska ${ }^{2}$, G. Stryganyuk ${ }^{2,3}$, A Gektin $^{3}$, A. Voloshinovskii ${ }^{2}$ \\ ${ }^{1}$ Faculty of Applied Sciences, Delft University of Technology, Mekelweg 15, $2629 \mathrm{JB}$ Delft, Netherlands. \\ 2 Ivan Franko National University of Lviv, Physics Department, 8 Kyryla i Mefodiya Str., 79005 Lviv, Ukraine. \\ 3 Institute for Scintillation Materials, NAS of Ukraine, 60 Lenin ave., 61001 Kharkiv, Ukraine.
}

(Dated: November 23, 2012)

\begin{abstract}
The excitation and emission properties of the lanthanides $\mathrm{Ce}^{3+}, \mathrm{Pr}^{3+}, \mathrm{Nd}^{3+}, \mathrm{Sm}^{3+}, \mathrm{Eu}^{3+}, \mathrm{Tb}^{3+}$, $\mathrm{Er}^{3+}, \mathrm{Tm}^{3+}$, and $\mathrm{Yb}^{3+}$ in $\mathrm{LiYP}_{4} \mathrm{O}_{12}$ were studied by vacuum ultra violet spectroscopy at $10 \mathrm{~K}$. It provides information on the energies of $4 \mathrm{f}-5 \mathrm{~d}$ excitation and emission bands. In the case of $\mathrm{Er}^{3+}$ spin forbidden emission was observed. Charge transfer excitation bands were identified for $\mathrm{Eu}^{3+}$, $\mathrm{Sm}^{3+}, \mathrm{Tm}^{3+}$, and $\mathrm{Yb}^{3+}$, and in the case of $\mathrm{Yb}^{3+}$ charge transfer luminescence is observed. All data appears to be consistent with each other and have been used to construct a level scheme showing the location of the energy levels of all trivalent and divalent lanthanides in $\mathrm{LiYP}_{4} \mathrm{O}_{12}$.
\end{abstract}

\section{INTRODUCTION}

The compounds $\mathrm{AREP}_{4} \mathrm{O}_{12}(\mathrm{~A}=\mathrm{Cs}, \mathrm{Rb}, \mathrm{K}, \mathrm{Na}, \mathrm{Li}$ and $\mathrm{RE}=\mathrm{La}, \mathrm{Pr}, \mathrm{Gd}, \mathrm{Y})$ form a family of related polyphosphate compounds, and luminescence properties of various lanthanide dopants in these compounds have been reported. Most studies deal with the luminescence of $\mathrm{Ce}^{3+}$ and $\mathrm{Pr}^{3+}$. $\mathrm{Ce}^{3+}$ luminescence in $\mathrm{LiLaP}_{4} \mathrm{O}_{12}$ was studied by Blasse and Dirksen [1], in $\mathrm{AGdP}_{4} \mathrm{O}_{12}(\mathrm{~A}=\mathrm{Cs}$, $\mathrm{K}, \mathrm{Na}, \mathrm{Li}$ ) by Zhong et al. [2], and recently we studied $\mathrm{Ce}^{3+}$ luminescence in $\mathrm{LiYP}_{4} \mathrm{O}_{12}[3]$ and $\mathrm{LiGdP}_{4} \mathrm{O}_{12}$ [4]. Srivastava et al. studied the photon cascade emission (PCE) of $\mathrm{Pr}^{3+}$ in $\mathrm{LiLaP}_{4} \mathrm{O}_{12}$ [5]. PCE emission is also observed in stoichiometric $\mathrm{LiPrP}_{4} \mathrm{O}_{12}[17] . \mathrm{Tb}^{3+}$ in $\mathrm{NaGdP}_{4} \mathrm{O}_{12}$ was studied by Zhong et al. [6], and stoichiometric $\mathrm{KTbP}_{4} \mathrm{O}_{12}$ by Kim et al. [7]. A few luminescence studies involving $\mathrm{Eu}^{3+}$ have appeared, i.e., $\mathrm{Eu}^{3+}$ in $\mathrm{LiLaP}_{4} \mathrm{O}_{12}$ [1] and $\mathrm{KEuP}_{4} \mathrm{O}_{12}$ [8]. Charge transfer luminescence was reported for $\mathrm{Yb}^{3+}$ in $\mathrm{LiYP}_{4} \mathrm{O}_{12}$ [9].

When we analyze the existing data it turns out that the redshift of the lowest $5 \mathrm{~d}$ state, i.e., its lowering in energy relative to its energy in the free lanthanide ion due to the crystal field, tends to decrease with smaller size of the alkaline (from $\mathrm{Cs}$, to $\mathrm{Rb}, \ldots$, to $\mathrm{Li}$ ) and with larger size of the rare earth (from Y, Gd to Pr, La). Therefore the redshift is smallest in $\mathrm{LiLaP}_{4} \mathrm{O}_{12}$ and, although experimental data is not yet available, it is expected to be largest in $\mathrm{CsYP}_{4} \mathrm{O}_{12}$.

The entire family of $\mathrm{AREP}_{4} \mathrm{O}_{12}$ compounds forms a nice study material because one may tune the redshift by selecting an appropriate combination of $\mathrm{A}$ and $\mathrm{RE}$. Although not much data is available we expect that the bandgap changes in a regular fashion with the size of $\mathrm{A}$ and RE too. It is of interest to study all the lanthanides in one and the same compound, and to establish where the lanthanide energy levels are located with respect to the valence and the conduction band. The spectroscopic information and the level scheme of that compound may then form a benchmark for the entire family of $\mathrm{AREP}_{4} \mathrm{O}_{12}$ compounds. Since $\mathrm{Y}^{3+}$ can be substituted by each trivalent lanthanide we decided to use $\mathrm{LiYP}_{4} \mathrm{O}_{12}$ as such potential benchmark and studied the spectroscopy of $\mathrm{Ce}^{3+}, \mathrm{Pr}^{3+}, \mathrm{Nd}^{3+}, \mathrm{Sm}^{3+}, \mathrm{Eu}^{3+}, \mathrm{Tb}^{3+}$,
$\mathrm{Er}^{3+}, \mathrm{Tm}^{3+}$, and $\mathrm{Yb}^{3+}$ under vacuum ultra violet excitation. We will identify the $4 \mathrm{f}-5 \mathrm{~d}$ transitions and the electron transfer bands in excitation spectra that enables us to place the energy levels of all the lanthanides within the band gap of $\mathrm{LiYP}_{4} \mathrm{O}_{12}$. We will show that the spectroscopy and the scheme resembles very much that of the well studied system $\mathrm{YPO}_{4}$ doped with trivalent lanthanides but that subtle differences can have large consequences for the luminescence and charge storage properties.

\section{EXPERIMENTAL}

The studies in this work were performed on powder samples of $\mathrm{LiY}_{1-x} \mathrm{Ln}_{x} \mathrm{P}_{4} \mathrm{O}_{12}$ ( $\mathrm{Ln}=\mathrm{Ce}, \mathrm{Pr}, \mathrm{Nd}, \mathrm{Sm}$, $\mathrm{Tb}, \mathrm{Er}, \mathrm{Tm}, \mathrm{Yb}$ ) polyphosphates synthesized using the melt-solution technique. For the synthesis, $\mathrm{Li}_{2} \mathrm{CO}_{3}$, $\mathrm{NH}_{4} \mathrm{H}_{2} \mathrm{PO}_{4}, \mathrm{Y}_{2} \mathrm{O}_{3}$ and an amount $\mathrm{x}=0.1$ of oxides of lanthanides were used as starting materials. These reagents were mixed and fired in quartz crucibles at $700^{\circ} \mathrm{C}$ for two hours. After cooling down to RT, the samples were washed with 0.1 molar $\mathrm{HNO}_{3}$ acid water and drained. The avarage size of the microcrystals was $5 \mu \mathrm{m}$, and the concentration of $\mathrm{Ln}^{3+}$ impurity in the final product was estimated to be in the $1-5 \mathrm{~mol} \%$ range. Analysis of XRD patterns of the studied powder samples confirms that they crystallize in the $\mathrm{LiNdP}_{4} \mathrm{O}_{12}$ structure type with $\mathrm{C} 2 / \mathrm{c}$ space group [10], and their crystallographic data are in agreement with those reported for $\mathrm{LiYP}_{4} \mathrm{O}_{12}$ in [11].

Measurements of luminescence excitation and emission spectra were performed at Deutsches Elektronen Synchotron (DESY, Hamburg) using synchrotron radiation from the DORIS III storage ring employing the SUPERLUMI experimental facility of HASYLAB [12]. A Helium flow-type cryostat was used to stabilize the temperature at $\mathrm{T}=10 \mathrm{~K}$. The emission in the UV-visible range was recorded with a spectral resolution of $0.3-5.0 \mathrm{~nm}$ using a $0.3 \mathrm{~m}$ ARC SpectraPro308 monochromator-spectrograph in Czerny-Turner mounting equipped with 1200 or 300 groves/mm gratings and a Princeton Instruments CCD detector $(1100 \times 300$ pixels $)$ 
or a HAMAMATSU R6358P photomultiplier. The VUV emission spectra were recorded with $2 \mathrm{~nm}$ resolution using a $0.5 \mathrm{~m}$ Pouey-type monochromator equipped with a solar blind Hamamatsu R6836 photomultiplier. Luminescence excitation spectra were scanned within the $3.7-10 \mathrm{eV}$ range with resolution of $0.32-0.06 \mathrm{~nm}$ using the primary $2 \mathrm{~m}$ monochromator in 15degrees McPherson mounting (equipped with a Jobin Yvon holographic concave grating with $\mathrm{Al}+\mathrm{MgF}_{2}$ coating and 1200 groves $/ \mathrm{mm}$ ). The primary monochromator was calibrated with $0.005 \mathrm{~nm}$ accuracy using the ${ }^{1} \mathrm{~S}_{0} \rightarrow{ }^{3} \mathrm{P}_{j}$ absorption of atomic xenon and krypton gases as a reference. Luminescence excitation spectra were corrected for the incident photon flux by using Na-salycilate as a reference.

\section{RESULTS}

The excitation and emission spectra of pure $\mathrm{LiYP}_{4} \mathrm{O}_{12}$ were reported already in Ref. [3, 9]. The excitation maximum of the phosphate groups $E^{e x}$ is at $10 \mathrm{~K}$ at 8.62 $\mathrm{eV}(144 \mathrm{~nm})$. Upon excitation in this band at low temperature, a $0.78 \mathrm{eV}$ broad self trapped exciton (STE) emission band peaking at $2.86 \mathrm{eV}$ is observed. In the excitation spectra of lanthanide luminescence in $\mathrm{LiYP}_{4} \mathrm{O}_{12}$ presented below, we can often recognize this phosphate group excitation. For some lanthanides it enhances the emission but for others it reduces emission intensity. It provides information on whether or not energy transfer from the excited phosphate groups to the lanthanide ion is efficient. Using the rule of thumb that the mobility edge is located approximately at 1.08 times the energy of exciton creation [13], we estimate the mobility edge in $\mathrm{LiYP}_{4} \mathrm{O}_{12}$ at $E_{V C}=9.3 \mathrm{eV}$ which is practically the same as for $\mathrm{YPO}_{4}[14]$.

\section{A. Ce coping}

The $10 \mathrm{~K}$ excitation and emission spectrum is shown in Fig. 1 where the five $4 \mathrm{f}-5 \mathrm{~d}$ excitation bands are clearly resolved at $4.18,5.14,5.40,5.63$, and $6.56 \mathrm{eV}$. The emission is the characteristic Ce doublet peaking at $3.98 \mathrm{eV}$ and $3.72 \mathrm{eV}$. The separation of $0.26 \mathrm{eV}$ is the expected spin orbit splitting between the ${ }^{2} \mathrm{~F}_{5 / 2}$ and ${ }^{2} F_{7 / 2}$ states. The Stokes shift of the emission to the ground state is 0.2 $\mathrm{eV}$ which is relatively small for $\mathrm{Ce}^{3+}$ in compounds. We studied $\mathrm{Ce}^{3+}$ in $\mathrm{LiYP}_{4} \mathrm{O}_{12}$ in a preceding paper where we showed that the so-called centroid shift and the total crystal field splitting of the 5 d-configuration agrees with predictions from empirical relationships [3]. In Fig. 1 the peak due to the phosphate group excitations at 8.6 $\mathrm{eV}$ is weak which indicates that the transfer efficiency of excitation energy to $\mathrm{Ce}^{3+}$ is rather poor. Between $E^{e x}$ and $E_{V C}$ the excitation efficiency of Ce emission is very low and above $9.3 \mathrm{eV}$ it starts to increase. Apparently unbound electrons and holes in the conduction band and valence band transfer excitation energy more efficiently to Ce than excitons do.

In [3] we presented a first tentative scheme with the energy levels of $\mathrm{Ce}^{3+}$ placed with respect to the top of the valence and the bottom of the conduction band of $\mathrm{LiYP}_{4} \mathrm{O}_{12}$. From an Arrhenius plot of the 5d-4f decay time as function of the temperature we estimated that the first $5 \mathrm{~d}$ state is located $0.75 \mathrm{eV}$ below the mobility edge. This implies that the $4 \mathrm{f}$ ground state is at 4.35 $\mathrm{eV}$ above the top of the valence band and that all four higher 5 d states are within the conduction band. Later in this work we will see that such placement is consistent with other data.

\section{B. Pr doping}

Figure 2 shows the excitation and emission spectra of $\mathrm{Pr}^{3+}$ in $\mathrm{LiYP}_{4} \mathrm{O}_{12}$. It is well established that the energy of the main $4 \mathrm{f}-5 \mathrm{~d}$ excitation bands for $\mathrm{Pr}^{3+}$ can be predicted from the corresponding energies observed for $\mathrm{Ce}^{3+}$ by simply adding $1.51 \pm 0.09 \mathrm{eV}$ energy [16]. In Fig. 2 we therefore also show the $\mathrm{Ce}^{3+}$ excitation spectrum from Fig. 1 but shifted to higher energy. A value of $1.57 \mathrm{eV}$ appears to provide a good match. One may recognize the main excitation bands, particularly the ones to $5 \mathrm{~d}_{1}, 5 \mathrm{~d}_{2}$, and $5 \mathrm{~d}_{5}$ of $\mathrm{Ce}^{3+}$ within the excitation spectrum for $\mathrm{Pr}^{3+}$ emission. However, each main $\mathrm{Pr}^{3+}$ excitation band is accompanied by satellite bands at higher energy. For example the $5 \mathrm{~d}_{1} \mathrm{Pr}^{3+}$ excitation band at $5.74 \mathrm{eV}$ is accompanied by two satellite bands at $5.98 \mathrm{eV}$ and 6.27 $\mathrm{eV}$. These satellite bands are due to the coupling between the electron in the $5 \mathrm{~d}$ orbital with the electron remaining in the $4 \mathrm{f}$ orbital. The same was observed for $\mathrm{Pr}^{3+}$ in $\mathrm{YPO}_{4}$ by van Pieterson et al. $[18,19]$ where also a theoretical explanation can be found. The excitations to $5 \mathrm{~d}_{2}, 5 \mathrm{~d}_{3}$, and $5 \mathrm{~d}_{4}$ build the broad structure between 6.45 $\mathrm{eV}$ and $7.75 \mathrm{eV}$. The emission bands at $5.48 \mathrm{eV}, 5.22 \mathrm{eV}$, $4.89 \mathrm{eV}$, and $4.71 \mathrm{eV}$ are identified as emissions from the lowest 4f5d state to the ${ }^{3} \mathrm{H}_{4},{ }^{3} \mathrm{H}_{5},\left[{ }^{3} \mathrm{H}_{6}\right.$ and $\left.{ }^{3} \mathrm{~F}_{2}\right]$, and $\left[{ }^{3} \mathrm{~F}_{3}\right.$ and $\left.{ }^{3} \mathrm{~F}_{4}\right]$ states of $\mathrm{Pr}^{3+}$, respectively. The Stokes shift for the emission to the ground state is $0.26 \mathrm{eV}$.

The excitation of the $4 \mathrm{f}^{2}\left[{ }^{1} \mathrm{~S}_{0}\right]$ state of $\mathrm{Pr}^{3+}$ is, as usually for $\mathrm{Pr}^{3+}$ in compounds, expected around $5.79 \mathrm{eV}$ $(214 \mathrm{~nm})$. The relaxed lowest energy $4 \mathrm{f} 5 \mathrm{~d}$ state is located below this $4 \mathrm{f}^{2}\left[{ }^{1} \mathrm{~S}_{0}\right]$ state, and photon cascade emission (PCE) from that $4 \mathrm{f}^{2}\left[{ }^{1} \mathrm{~S}_{0}\right]$ state is not possible. The situation for PCE is more favorable in $\mathrm{LiPrP}_{4} \mathrm{O}_{12}$ and $\mathrm{LiLaP}_{4} \mathrm{O}_{12}[5,17]$. Because the ionic radius of $\operatorname{Pr}^{3+}$ and $\mathrm{La}^{3+}$ is larger than that of $\mathrm{Y}^{3+}$, the crystal field interaction with the $5 \mathrm{~d}$ electron is somewhat smaller; just enough to locate the lowest $5 \mathrm{~d}$ state above the ${ }^{1} \mathrm{~S}_{0}$ state and PCE can occur.

\section{Nd doping}

Figure 3 shows the excitation and emission spectra for $\mathrm{Nd}^{3+}$ in $\mathrm{LiYP}_{4} \mathrm{O}_{12}$. Usually the lowest $5 \mathrm{~d}$ state of $\mathrm{Nd}^{3+}$ 
is at about $2.80 \mathrm{eV}$ higher energy than that for $\mathrm{Ce}^{3+}[20]$. Therefore in Fig. 3 we have shown the first four $\mathrm{Ce}^{3+}$ excitation bands shifted by $2.77 \mathrm{eV}$ in energy. Only the first band in the $\mathrm{Nd}$ exciton spectrum at $6.95 \mathrm{eV}$ can be identified as the transition to the lowest energy $5 \mathrm{~d}_{1}$ state. The two electrons that are still in the $4 \mathrm{f}$-orbital may occupy different energy states that couple with the electron in $5 \mathrm{~d}$. This makes interpretation of the Nd excitation spectrum at higher energies very complicated. The emission to the $4 \mathrm{f}^{3}\left[{ }^{4} \mathrm{I}_{9 / 2}\right]$ ground state is observed as a clear band at $6.75 \mathrm{eV}$ nm yielding a Stokes shift of $0.2 \mathrm{eV}$; similar to that for $\mathrm{Ce}^{3+}$. The emission to the $4 \mathrm{f}^{3}\left[{ }^{4} \mathrm{I}_{11 / 2}\right]$ state is observed as a clear band at $6.51 \mathrm{eV}$. The emission to the ${ }^{4} \mathrm{I}_{13 / 2}$ and ${ }^{4} \mathrm{I}_{15 / 2}$ states, that are predicted at 6.26 $\mathrm{eV}$ and $6.02 \mathrm{eV}$, are not observed as resolved emission bands. The bands around $5.32 \mathrm{eV}$ and $4.66 \mathrm{eV}$ are due to transition to higher energy $4 \mathrm{f}^{3}$ states. Like for $\mathrm{Ce}^{3+}$ and $\mathrm{Pr}^{3+}$ the excitation efficiency is negligible near the mobility edge at $9.3 \mathrm{eV}$.

\section{Sm doping}

Figure 4 shows the excitation and emission spectra for $\mathrm{Sm}^{3+}$ in $\mathrm{LiYP}_{4} \mathrm{O}_{12}$. $\mathrm{Sm}^{3+}$ has never been observed to show 5d-4f emission in compounds because of rapid relaxation from the lowest $4 \mathrm{f}^{4} 5 \mathrm{~d}_{1}$ state to lower energy $4 \mathrm{f}^{5}$ states. The sharp emission lines at $2.212 \mathrm{eV}, 2.066 \mathrm{eV}$, and $1.913 \mathrm{eV}$ in Fig. 4 are attributed to $4 \mathrm{f}^{5}-4 \mathrm{f}^{5}$ transitions starting from the ${ }^{4} \mathrm{G}_{5 / 2}$ and ending at the ${ }^{6} \mathrm{H}_{5 / 2}$ ground state and higher energy ${ }^{6} \mathrm{H}_{7 / 2}$, and ${ }^{6} \mathrm{H}_{9 / 2}$ states, respectively. The first $4 \mathrm{f}^{5} \rightarrow 4 \mathrm{f}^{4} 5 \mathrm{~d}$ excitation of $\mathrm{Sm}^{3+}$ is always at $3.22 \mathrm{eV}$ higher energy than that of $\mathrm{Ce}^{3+}$ and is then predicted at $7.38 \mathrm{eV}$. We therefore assign the band at $7.43 \mathrm{eV}$ in Fig. 4 to that excitation. The relatively narrow band is located on top of a much broader excitation band that we attribute to the charge transfer (CT) band, i.e., electron transfer from the top of the valence band to $\mathrm{Sm}^{3+}$. The maximum of this CT band is estimated around $7.35 \mathrm{eV}$. The $4 \mathrm{f} 5 \mathrm{~d}$ excitation features on top of a broad underlying CT band are very similar as in [18] for $\mathrm{Sm}^{3+}$ in $\mathrm{YPO}_{4}$. A main difference is that the CT band in $\mathrm{LiYP}_{4} \mathrm{O}_{12}$ is at somewhat higher energy than in $\mathrm{YPO}_{4}$ and shifted more underneath the $4 \mathrm{f} 5 \mathrm{~d}$ bands. Note that the excitation intensity starts to drop steeply above $8.6 \mathrm{eV}$ where the phosphate groups are being excited.

\section{E. Eu doping}

Figure 5 shows the excitation and emission spectra for $\mathrm{Eu}^{3+}$ in $\mathrm{LiYP}_{4} \mathrm{O}_{12}$. Like for $\mathrm{Sm}^{3+}$, 5d-4f emission is never observed with $\mathrm{Eu}^{3+}$ and the emission spectrum shows only $4 \mathrm{f}^{6}-4 \mathrm{f}^{6}$ emission lines at $2.103 \mathrm{eV}, 2.032 \mathrm{eV}$, $1.912 \mathrm{eV}$ (weak), $1.780 \mathrm{eV}$ due to the ${ }^{5} \mathrm{D}_{0} \rightarrow{ }^{7} \mathrm{~F}_{J}(\mathrm{~J}=1,2$, 3 , and 4) $4 \mathrm{f}^{6}-4 \mathrm{f}^{6}$ transitions. The excitation band to the lowest energy $4 \mathrm{f}^{5} 5 \mathrm{~d}$ state is expected at $4.38 \mathrm{eV}$ higher energy than that for $\mathrm{Ce}^{3+}$ yielding a predicted value of
$8.55 \mathrm{eV}$. This is at slightly lower energy than the phosphate excitation band at $8.62 \mathrm{eV}$. Figure 5 reveals a clear excitation band at $8.50 \mathrm{eV}$ that we attribute to the first 4f5d excitation band of $\mathrm{Eu}^{3+}$. Like for the $\mathrm{Sm}^{3+}$ excitation, the intensity drops steeply the moment phosphate groups are being excited, i.e. above $8.6 \mathrm{eV}$. The strong and broad excitation starting at $5.2 \mathrm{eV}$ is like for $\mathrm{Sm}^{3+}$ attributed to the $\mathrm{CT}$ band, i.e., an electron is excited from the top of the valence band to $\mathrm{Eu}^{3+}$. The maximum of the CT-band is located at $6.20 \mathrm{eV}$. This is at relatively high energy for $\mathrm{Eu}^{3+}$ in an oxide compound. One reason is the strong binding of the oxygen ligands in the polyphosphate compound. Another reason is the relatively small yttrium site size. For example in $\mathrm{KEuP}_{4} \mathrm{O}_{12}$ with the larger Eu rare earth the $\mathrm{CT}$ band peaks at 5.44 $\mathrm{eV}$ [8], and in $\mathrm{LiLaP}_{4} \mathrm{O}_{12}$ with the even larger La rare earth the CT band was reported to be located at 4.68 $\mathrm{eV}$ [1]. Similar observations as function of rare earth site size were reported for other families of related compounds $[13,21]$.

It is well established that once the energy of CT to $\mathrm{Eu}^{3+}$ is known the energy of CT to any other trivalent lanthanide can be predicted [22]. That for $\mathrm{Sm}^{3+}$ is always at $1.25 \mathrm{eV}$ higher energy than that for $\mathrm{Eu}^{3+}[20]$. To demonstrate this we have shifted the excitation spectrum for $\mathrm{Eu}^{3+}$ upward by $1.20 \mathrm{eV}$ and drawn it in Fig. 4. It provides an impression of the contribution from the $\mathrm{Sm}$ CT band to the excitation spectrum.

\section{F. Tb doping}

$\mathrm{Tb}^{3+}$ has eight electrons in the $4 \mathrm{f}$ orbital and upon excitation of one electron to the $5 \mathrm{~d}$ orbital the seven remaining electrons in $4 \mathrm{f}$ will occupy the lowest energy ${ }^{8} \mathrm{~S}_{7 / 2}$ state with seven aligned electron spins. The electron in $5 \mathrm{~d}$ can like for $\mathrm{Ce}^{3+}$ occupy the five crystal field split $5 \mathrm{~d}$ states. The splitting is expected to be very similar as for $\mathrm{Ce}^{3+}$ in $\mathrm{LiYP}_{4} \mathrm{O}_{12}$. In addition, the $5 \mathrm{~d}$ electron may orient its spin parallel or anti-parallel to the total spin of the ${ }^{8} \mathrm{~S}_{7 / 2}$ state. One then expects two sets of five excitation bands. A lower energy set due to weak spin-forbidden transitions to the so-called high spin [HS] states, and a higher energy set due to the spin allowed transition to the low spin [LS] states.

Figure 6 shows the excitation and emission spectra of $\mathrm{Tb}^{3+}$. The emission is very characteristic $\mathrm{Tb}^{3+}$ emission originating from the $4 \mathrm{f}^{8}\left[{ }^{5} \mathrm{D}_{3}\right]$ and $4 \mathrm{f}^{8}\left[{ }^{5} \mathrm{D}_{4}\right]$ states and terminating at ${ }^{7} \mathrm{~F}_{J}$ multiples. The spin-allowed transition to the $[\mathrm{LS}] 5 \mathrm{~d}_{1}$ state is always found at $1.66 \pm 0.12 \mathrm{eV}$ higher energy than that for $\mathrm{Ce}^{3+}[16]$. The corresponding excitation band for $\mathrm{Tb}^{3+}$ is then predicted at 5.82 eV which perfectly agrees with Fig. 6. The weak excitation band at $0.96 \mathrm{eV}$ lower energy, at $4.86 \mathrm{eV}$, must then be attributed to the first spin-forbidden transition to the $[\mathrm{HS}] 5 \mathrm{~d}_{1}$ state.

The dashed curve 1) in Fig. 6 shows the $\mathrm{Ce}^{3+}$ excitation spectrum shifted in energy by $1.64 \mathrm{eV}$. Note that 
the locations of the first four excitation bands then agree very well with observed bands for $\mathrm{Tb}^{3+}$. The fifth excitation band of $\mathrm{Tb}^{3+}$ at $8.10 \mathrm{eV}$ is at $0.12 \mathrm{eV}$ lower energy than predicted from the $\mathrm{Ce}^{3+}$ excitation spectrum. It suggests that the total crystal field splitting for $\mathrm{Tb}^{3+}$ is $0.12 \mathrm{eV}$ smaller than that observed for $\mathrm{Ce}^{3+}$ and $\mathrm{Pr}^{3+}$. Slight changes in crystal field splitting when going from $\mathrm{Ce}^{3+}$ towards $\mathrm{Yb}^{3+}$ are possible due to the lanthanide contraction. Together with the $[\mathrm{LS}] 5 \mathrm{~d}_{1}$ excitation band at $5.82 \mathrm{eV}$, we observe at least two satellite bands at 5.93 and $6.15 \mathrm{eV}$. They are at about $1 \mathrm{eV}$ lower energy than the spin allowed transitions to $[\mathrm{LS}] 5 \mathrm{~d}_{3}$ and $[\mathrm{LS}] 5 \mathrm{~d}_{4}$, and are therefore attributed to spin forbidden transitions to the $[\mathrm{HS}] 5 \mathrm{~d}_{3}$ and $[\mathrm{HS}] 5 \mathrm{~d}_{4}$ states. The spin forbidden transition to $[\mathrm{HS}] 5 \mathrm{~d}_{2}$ is predicted to coincide with the transition to $[\mathrm{LS}] 5 \mathrm{~d}_{1}$. To illustrate this further we have drawn in Fig. 6 the excitation spectrum of $\mathrm{Ce}^{3+}$ shifted by $0.64 \mathrm{eV}$. The excitation bands for $\mathrm{Ce}^{3+}$ then approximately reproduce the energies for the transitions to the $[\mathrm{HS}] 5 \mathrm{~d}_{i}$ states of $\mathrm{Tb}^{3+}$.

\section{G. Er doping}

$\mathrm{Er}^{3+}$ has 11 electrons in the $4 \mathrm{f}$ orbital, and upon excitation of one of the electrons to the $5 \mathrm{~d}$ orbital the remaining 10 electrons may find themselves in one of the $4 \mathrm{f}^{10}$ excited states. The first spin allowed $4 \mathrm{f}-5 \mathrm{~d}$ transition to the $[\mathrm{LS}] 5 \mathrm{~d}_{1}$ state of $\mathrm{Er}^{3+}$ is on average at 3.74 eV higher energy than for $\mathrm{Ce}^{3+}$ and we therefore predict the $\mathrm{Er}^{3+}$ transition at $7.92 \mathrm{eV}$. The $\mathrm{Er}^{3+}$ excitation spectrum shown in Fig. 7 has its main maximum at $7.98 \mathrm{eV}$ that we attribute to the transition to the $[\mathrm{LS}] 5 \mathrm{~d}_{1}$ state. Like for $\mathrm{Tb}^{3+}$ the spin forbidden transition to the $[\mathrm{HS}] 5 \mathrm{~d}_{1}$ state is at lower energy. The emission lines in Fig. 7 can all be assigned to spin forbidden transitions from this $[\mathrm{HS}] 5 \mathrm{~d}_{1}$ state to states of the $4 \mathrm{f}^{11}$ configuration. Then, by adding the energy of the Stokes shift observed for $\mathrm{Ce}, \mathrm{Pr}$, and $\mathrm{Nd}$ (on average $0.22 \mathrm{eV}$ ) to the $7.20 \mathrm{eV}$ energy of the emission to the ground state we obtain a pretty good estimate of $7.42 \mathrm{eV}$ for the excitation band energy belonging to $[\mathrm{HS}] 5 \mathrm{~d}_{1}$. This value coincides with the shoulder band observed in the excitation spectrum of $\mathrm{Er}^{3+}$. The energy difference between the [LS] and [HS] state is therefore $0.66 \mathrm{eV}$.

\section{H. Tm doping}

The excitation and emission spectra of $\mathrm{Tm}^{3+}$ are shown in Fig. 8. The first spin forbidden and spin allowed transitions to the $[\mathrm{HS}] 5 \mathrm{~d}_{1}$ and $[\mathrm{LS}] 5 \mathrm{~d}_{1}$ states are at $7.52 \mathrm{eV}$ and $7.89 \mathrm{eV}$. The exchange splitting between the $[\mathrm{LS}]$ and $[\mathrm{HS}]$ states is therefore $0.37 \mathrm{eV}$. Usually the CT to $\mathrm{Tm}^{3+}$ is at $1.72 \mathrm{eV}$ higher energy than the CT to $\mathrm{Eu}^{3+}$, and the CT band of Tm is therefore predicted at $7.92 \mathrm{eV}$. The situation is similar as for $\mathrm{Sm}^{3+}$ in Fig. 4 where the broad CT band is also underneath the nar- rower $4 \mathrm{f} 5 \mathrm{~d}$ excitation bands. The predicted location of $7.92 \mathrm{eV}$ is consistent with the $\mathrm{Tm}^{3+}$ excitation spectrum. Like for $\mathrm{Sm}^{3+}$ and $\mathrm{Eu}^{3+}$, the excitation intensity drops sharply the moment phosphate groups are being excited, i.e., above $E^{e x}=8.62 \mathrm{eV}$. To illustrate what the CT-band of $\mathrm{Tm}^{3+}$ would look like, we have drawn in Fig. 8 the energy shifted CT-band observed for $\mathrm{Yb}^{3+}$ in Fig. 9. The $\mathrm{Yb}^{3+}$ excitation spectrum was shifted by $1.29 \mathrm{eV}$, i.e., the average energy difference between the CT band energy for Tm as compared to $\mathrm{Yb}[20]$. 5d-4f emission is not observed for $\mathrm{Tm}^{3+}$; most likely because it is quenched via the CT state. Instead only $4 \mathrm{f}^{12}-4 \mathrm{f}^{2}$ emissions are excited.

\section{Yb doping}

The excitation and emission spectra of $\mathrm{Yb}^{3+}$ are shown in Fig. 9. The excitation spectrum is dominated by a $1.4 \mathrm{eV}$ broad (FWHM) charge transfer band peaking at $6.59 \mathrm{eV}$. The $\mathrm{Yb}^{3+} \mathrm{CT}$ band in compounds is on average found $0.43 \mathrm{eV}$ higher in energy than the $\mathrm{Eu}^{3+} \mathrm{CT}$ band $[20,22]$. The observed position of the $\mathrm{Yb}^{3+} \mathrm{CT}$-band is therefore in excellent agreement with that of $\mathrm{Eu}^{3+}$ in $\mathrm{LiYP}_{4} \mathrm{O}_{12}$. The first $4 \mathrm{f}-5 \mathrm{~d}$ excitation band in $\mathrm{Yb}^{3+}$ is expected at energies higher than the band gap and is not observed in Fig. 9. A faint peak due to excitation of the phosphate group is present at $8.6 \mathrm{eV}$. The emission spectrum is attributed to charge transfer luminescence. The transition to the $\mathrm{Yb}^{3+}{ }^{2} \mathrm{~F}_{7 / 2}$ ground state gives the emission band a $3.59 \mathrm{eV}$, and therefore the Stokes shift is $3 \mathrm{eV}$ large. The second emission band with a maximum near $2.57 \mathrm{eV}$ must be attributed to the transition to the ${ }^{2} \mathrm{~F}_{5 / 2}$ excited state of $\mathrm{Yb}^{3+}$. The about four times lower intensity of ${ }^{2} \mathrm{~F}_{5 / 2}$ emission as compared to ${ }^{2} \mathrm{~F}_{7 / 2}$ emission is commonly observed for CT luminescence involving $\mathrm{Yb}^{3+}$. One reason for the lower intensity is the scaling of radiative lifetime, and therewith intensity, with the third power of the emission wavelength. This already accounts for a factor of 2.8 intensity difference.

$\mathrm{Yb}^{3+}$ doped $\mathrm{LiYP}_{4} \mathrm{O}_{12}$ was also studied in [9] where the two CT-luminescence bands at $2.8 \mathrm{eV}$ and $4.04 \mathrm{eV}$ and the excitation band peaked at $5.99 \mathrm{eV}$ were observed. These values are significantly different from what we find in Fig. 9. Both the CT-emission and the CT-excitation spectra appear similar in position and shape as spectra presented by Nakazawa [23] on $\mathrm{Yb}^{3+}$ doped $\mathrm{YPO}_{4}$. It suggest that the sample studied in Ref. [9] contained an $\mathrm{YPO}_{4}$ impurity phase that dominated the luminescence and excitation spectra.

\section{DISCUSSION}

With the value for the first $4 \mathrm{f}-5 \mathrm{~d}$ excitation band of $\mathrm{Ce}^{3+}$ in $\mathrm{LiYP}_{4} \mathrm{O}_{12}$, the first $4 \mathrm{f}-5 \mathrm{~d}$ excitation band for all other trivalent lanthanides in $\mathrm{LiYP}_{4} \mathrm{O}_{12}$ can be predicted by using the (parameter) values for the first $4 \mathrm{f}-5 \mathrm{~d}$ transitions of the free (gasseous) lanthanide ions. In column 4 
of Table I we have compiled those predicted values using the most recent parameter values from [20]. Column 3 compiles the observed energies and the agreement is evident. For the heavy lanthanides $\mathrm{Tb}^{3+}, \mathrm{Er}^{3+}$, and $\mathrm{Tm}^{3+}$ also the energy of the first spin allowed transitions is compiled (shown within brackets). The CT band energies of all lanthanides in a specific compound can be predicted once that of $\mathrm{Eu}^{3+}$ in that compound is known. By using the parameter values and the method outlined in [20] best estimates are made and they are compiled in column 6 of Table I. The energies of the observed CT-bands for $\mathrm{Sm}^{3+}, \mathrm{Eu}^{3+}, \mathrm{Tm}^{3+}$, and $\mathrm{Yb}^{3+}$ are compiled in column 5 and all agree well with expectation.

We have now sufficient information to place all the lanthanide levels with respect to the valence and conduction band of $\mathrm{LiYP}_{4} \mathrm{O}_{12}$. The results are shown in Fig. 10. The dashed line at $E^{e x}=8.62 \mathrm{eV}$ denotes the energy of excitation of the phosphate group. The bottom of the conduction band is estimated at $1.08 \times 8.62$ or $9.3 \mathrm{eV}$ above the top of the valence band. The observed and predicted CT energies in Table I provide us with the location of the ground state of the divalent lanthanide ions in $\mathrm{LiYP}_{4} \mathrm{O}_{12}$. The curve labeled $4 \mathrm{f}(2+)$ connects the predicted CT energies from column 6 of Table I. The ground state energy of $\mathrm{Ce}^{3+}$ was estimated in [3] at 4.3 $\mathrm{eV}$ above the top of the valence band, and from that the ground state energies of all other trivalent lanthanides are known as well by using the parameters compiled in [20]. The curve labeled $4 \mathrm{f}(3+)$ connects those energies. We can now add the Dieke diagram to place all the excited $4 \mathrm{f}$ states in the scheme; these are the horizontal bars in Fig. 10. The curve labeled $5 \mathrm{~d}(3+)$ connects the energies of the first $5 \mathrm{~d}$ states of the trivalent lanthanides. For $\mathrm{Ce}^{3+}$ we have also drawn all five excited 5 d energies and for $\mathrm{Tb}^{3+}, \mathrm{Er}^{3+}$, and $\mathrm{Tm}^{3+}$ the energies of the first low spin $5 \mathrm{~d}$ states are shown.

For comparison we show in Fig. 11 the level scheme for $\mathrm{YPO}_{4}$ as presented in [14]. In $\mathrm{YPO}_{4}$ the lanthanide ion will like in $\mathrm{LiYP}_{4} \mathrm{O}_{12}$ substitute for an yttrium cation. The anion coordination around yttrium is like in $\mathrm{LiYP}_{4} \mathrm{O}_{12}$ eight-fold in the form of a dodecahedron. The average $\mathrm{Y}-\mathrm{O}$ bond length is $234 \mathrm{pm}$ which is quite close to that $(239 \mathrm{pm})$ of $\mathrm{LiYP}_{4} \mathrm{O}_{12}$. The point symmetry is different, i.e. $D_{2 d}$ for $\mathrm{YPO}_{4}$ and $C_{2}$ for $\mathrm{LiYP}_{4} \mathrm{O}_{12}$. At first sight both schemes appear very similar but there are subtle differences. The bandgap of $\mathrm{LiYP}_{4} \mathrm{O}_{14}$ is slightly $(0.1 \mathrm{eV})$ larger. The energy for the CT-bands are almost $0.5 \mathrm{eV}$ higher in $\mathrm{LiYP}_{4} \mathrm{O}_{12}$ and this brings the ground state energies of the divalent lanthanides $0.4 \mathrm{eV}$ closer to the mobility edge than in $\mathrm{YPO}_{4}$. This would imply that trivalent lanthanides in $\mathrm{LiYP}_{4} \mathrm{O}_{12}$ trap electrons $0.4 \mathrm{eV}$ less deep than in $\mathrm{YPO}_{4}$. Note that the ground state energy of $\mathrm{Ce}^{3+}$ in $\mathrm{LiYP}_{4} \mathrm{O}_{12}$ is about $0.3 \mathrm{~V}$ higher above the valence band than in $\mathrm{YPO}_{4}$. This together with a large $4 \mathrm{f}-5 \mathrm{~d}$ difference in $\mathrm{LiYP}_{4} \mathrm{O}_{12}$ brings the lowest energy $5 \mathrm{~d}$ states $0.7 \mathrm{eV}$ closer to the mobility edge than in $\mathrm{YPO}_{4}$. As a consequence the $5 \mathrm{~d}-4 \mathrm{f}$ emission of $\mathrm{Ce}^{3+}$ is expected to be less temperature stable than in $\mathrm{YPO}_{4}$. A parame- ter of importance for the level scheme is the energy differences between the $4 \mathrm{f}(2+)$ and $4 \mathrm{f}(3+)$ curves. For $\mathrm{Eu}$ that energy difference was found $7.0 \mathrm{eV}$ in $\mathrm{YPO}_{4}$. In the scheme for $\mathrm{LiYP}_{4} \mathrm{O}_{12}$ the value is $7.1 \mathrm{eV}$. For other compounds like $\mathrm{SrAl}_{2} \mathrm{O}_{4}, \mathrm{LaBr}_{3}, \mathrm{CaGa}_{2} \mathrm{~S}_{4}$, and $\mathrm{GaN}$ similar type of schemes were published [24-27]. Although a different parameter set than in [20] was used, the method of construction was the same as in this work for $\mathrm{LiYP}_{4} \mathrm{O}_{12}$ and $\mathrm{YPO}_{4}$. The collection of level schemes provides an impression how the level energies and properties of materials may change with type of anion in the compound. Energy level schemes based on X-ray photoelectron spectroscopy and ultra violet spectroscopy experiments on lanthanide doped $\mathrm{LaF}_{3}$ and $\mathrm{Y}_{3} \mathrm{Al}_{5} \mathrm{O}_{12}$ have been published in [28].

In this work we have obtained the values $\Delta E^{e x}$ of the exchange splitting between the $[\mathrm{LS}] 5 \mathrm{~d}_{1}$ and $[\mathrm{HS}] 5 \mathrm{~d}_{1}$ states of $\mathrm{Tb}^{3+}, \mathrm{Er}^{3+}$, and $\mathrm{Tm}^{3+}$. The size of this splitting depends both on the type of compounds and on the type of lanthanide ion. This was analyzed in detail in [16]. Among the four lanthanides, the splitting is largest for $\mathrm{Tb}^{3+}\left(0.97 \mathrm{eV}\right.$ in $\left.\mathrm{LiYP}_{4} \mathrm{O}_{12}\right)$ because the spin of the $5 \mathrm{~d}$ electron interacts with seven aligned spins in the $4 \mathrm{f}$ orbital. In the case of $\mathrm{Er}^{3+}$ the interaction is with four aligned spins and for $\mathrm{Tm}^{3+}$ with 3 alligned spins. The exchange splitting decreases to $0.56 \mathrm{eV}$ for Er and 0.37 $\mathrm{eV}$ for Tm. Figure 12 is reproduced from [16] and shows that the exchange splitting scales linearly with the socalled spectroscopic polarizability $\alpha_{\text {calc }}$. This is a parameters that can be obtained with a simple calculation from the electronegativity of the cations present in the compound [16]. The data point for $\mathrm{Tb}^{3+}$ in $\mathrm{LiYP}_{4} \mathrm{O}_{12}$ falls nicely within this empirically found behavior. In Fig. 12 we have also marked the data points for $\mathrm{GdAlO}_{3}$ and $\mathrm{Lu}_{2} \mathrm{O}_{3}$. These compounds have lower electronegative cations than the phosphates, the binding of the oxygen ligands is then smaller. It does not only decrease the exchange splitting but also the band gap, and it increased the centroid shift of the $5 \mathrm{~d}$ configuration. The polyphosphates $\mathrm{AREP}_{4} \mathrm{O}_{12}$ contain a large fraction of strongly bonding phosphate atoms, and that is the reason that the exchange splitting and bandgap are amongst the largest, and the centroid shift amongst the smallest of the entire oxide family. Only fluorides like $\mathrm{LiYF}_{4}$ show more extreme values.

\section{CONCLUDING REMARKS}

In this work we have studied the spectroscopy of $\mathrm{Ce}^{3+}$, $\mathrm{Pr}^{3+}, \mathrm{Nd}^{3+}, \mathrm{Sm}^{3+}, \mathrm{Tb}^{3+}, \mathrm{Er}^{3+}, \mathrm{Tm}^{3+}$, and $\mathrm{Yb}^{3+}$ in $\mathrm{LiYP}_{4} \mathrm{O}_{12}$. The found energies for $4 \mathrm{f} 5 \mathrm{~d}$ excitation bands and CT-bands appear fully consistent with each other. Once we know the 4f-5d excitation energy for $\mathrm{Ce}^{3+}$ that of all other lanthanides can be predicted and predictions agree with experiment. The same applies for the predicted CT-band energies. A level scheme with all the divalent and trivalent lanthanide energy levels has been 
constructed. The scheme appears very similar to that of $\mathrm{YPO}_{4}$ nevertheless differences of the order of few tenths of an $\mathrm{eV}$ are present. This may seem small on the scale of the band gap energy but few $0.1 \mathrm{eV}$ energy difference may be very important for the performance of the material as a luminescence or a charge carrier storage material.

In principle, knowledge on the energy of the phosphate group excitation, the redshift for the $\mathrm{Ce}^{3+} 5 \mathrm{~d}$-state, and the CT energy for $\mathrm{Eu}^{3+}$ in a $\mathrm{AREP}_{4} \mathrm{O}_{12}$ compound is already sufficient to draw all lanthanide level in a scheme like in Fig. 10. For the entire family of $\mathrm{AREP}_{4} \mathrm{O}_{12}$ polyphosphate compounds one may expect a quite similar level scheme as for $\mathrm{LiYP}_{4} \mathrm{O}_{12}$, but also then subtle differences may have large consequences for the spectroscopic and charge storage properties. The bandgap may change few tenths of an eV within this family. That also applies to the redshift of the lowest $5 \mathrm{~d}$ state. The largest changes are to be expected in the energy of charge transfer.

\section{ACKNOWLEDGEMENTS}

These works are partially supported by the Ukraine Ministry of Science and Education (project No. 0109U002075). The authors appreciate the support of HASYLAB (DESY, Hamburg) for the Superlumi experiments.
[1] G. Blasse, G.J. Dirksen, Phys. Stat. Sol. (b) 110 (1982) 487.

[2] Jiuping Zhong, Hongbin Liang, Huihong Lin, Bing Han, Qiang Su, Guobin Zhang, J. Mater. Chem. 17 (2007) 4679.

[3] T. Shalapska, G. Stryganyuk,A. Gektin, P. Demchenko, A. Voloshinovskii, P. Dorenbos J. Phys.: Cond. Matter, in press (2010).

[4] T. Shalapska, G. Stryganyuk, P. Demchenko, A. Voloshinovskii, P. Dorenbos, J. Physics Cond. Matter 21 (2009) 445901

[5] A.M. Srivastava, A.A. Setlur, H.A. Comanzo, M.E. Hannah, P.A. Schmidt, U. Happek, J. Lumin. 129 (2009) 126.

[6] Jiuping Zhong, Hongbin Liang, Bing Han, Qiang Su, Ye Tao, Chem. Phys. Lett. 453 (2008) 192.

[7] Chang-Hong Kim, Il-Eok Kwon, Cheol-Hee Park, YoungJu Hwang, Hyun-Sook Bae, Byung-Yong Yu, Chong-Hog Pyun, Guang-Yan Hong, J. Alloys and Compounds 311 (2000) 33.

[8] Jing Zhu, Wen-Dan Cheng, Hao Zhang, Yu-De Wang, J. Lumin. 129 (2009) 1326.

[9] G. Stryganyuk, S. Zazubovich, A. Voloshinovskii, M. Pidzyrailo, G. Zimmerer, R. Peters, K. Petermann, J. Phys. Cond. Matter 19 (2007) 036202.

[10] H. Koizumi, Acta Crystallographica B32(1976) 266.

[11] Z. Mazurak, E. Lukowiak, B. Jezowska-Trzebiatcwska, Z. Ciunik, D. Jezowska-Trezebiatcwska, Z. Ciunik, D. Scilultze, C.H. Waligora, J Molecular Struc. 115(1984) 31.

[12] G. Zimmerer, Radiat. Meas. 42 (2007) 859.

[13] P. Dorenbos, J. Lumin. 111 (2005) 89.

[14] N.R.J. Poolton, A.J.J. Bos, G.O. Jones, P. Dorenbos, J. Phys. Cond. Mat. 22 (2010) 185403.

[15] T. Shalapska, G. Stryganyuka, D. Trotsc, T. Demkiv, A. Gektin, A. Voloshinovskii, P. Dorenbos, J. Lumin 130 (2010) 1941.

[16] P. Dorenbos, J. Phys.: Condens. Matter 15 (2003) 6249.

[17] T. Shalapska, G. Stryganyuk, Yu Romanysghyn, D. Trots, P. Demchenko, A. Gektin, A. Voloshinovskii, P. Dorenbos, J. Phys. D: Appl. Phys. 43 (2010) 405404.

[18] L. van Pieterson, M.F. Reid, R.T. Wegh, S. Soverna, A. Meijerink, Phys. Rev. B65 (2002) 045113.

[19] L. van Pieterson, M.F. Reid, G.W. Burdick, A. Meijerink,
Phys. Rev. B65 (2002) 045114.

[20] P. Dorenbos, A.H. Krumpel, E. van der Kolk, P. Boutinaud, M. Bettinelli, E. Cavalli, Optical Materials 32 (2010) 1681.

[21] G. Blasse, J. Sol. State Chem. 4 (1972) 52.

[22] P. Dorenbos, J. Phys.: Condens. Matter 15 (2003) 8417.

[23] E. Nakazawa, J. Lumin. 18/19 (1979) 272.

[24] P. Dorenbos, J. Electrochem. Soc. 152 (2005) H107-H110.

[25] P. Dorenbos, E.V.D. van Loef, A.P. Vink, E. van der Kolk, C.W.E. van Eijk, K.W. Krämer, H.U. Güdel, W.M. Higgins, K. Shah, J. Lumin.117 (2006) 147.

[26] A. Bessiere, P. Dorenbos, C.W.E. van Eijk, E. Yamagishi, C. Hidaka, T. Takizawa, J. Electrochem. Soc. 151(12) (2004) H254.

[27] P. Dorenbos, E. van der Kolk, Applied Physics Letters, 89 (2006) 061122.

[28] C.W. Thiel, R.L. Cone, J. Lumin., in press October 2010, doi:10.1016/j.jlumin.2010.09.025. 


\section{TABLES}

TABLE I: Observed and predicted energies for the first 4f5 d transition $E_{f d}$ and for the CT-band energy $E^{C T}$. Values within brackets are for the first spin allowed $4 \mathrm{f}-5 \mathrm{~d}$ transition. All energies are in $\mathrm{eV}$.

\begin{tabular}{|c|c|c|c|c|c|}
\hline $\mathrm{Ln}^{3+}$ & $\mathrm{n}$ & $E_{f d}(o b s)$ & $E_{f d}($ pred $)$ & $\Delta E^{C T}($ obs $)$ & $E^{C T}($ pred $)$ \\
\hline $\mathrm{La}$ & 0 & - & - & - & 11.8 \\
\hline $\mathrm{Ce}$ & 1 & 4.13 & 4.13 & - & 10.3 \\
\hline $\operatorname{Pr}$ & 2 & 5.74 & 5.64 & - & 9.07 \\
\hline $\mathrm{Nd}$ & 3 & 6.95 & 6.93 & - & 8.63 \\
\hline Pm & 4 & - & 7.25 & - & 8.54 \\
\hline $\mathrm{Sm}$ & 5 & 7.43 & 7.35 & 7.35 & 7.45 \\
\hline $\mathrm{Eu}$ & 6 & 8.50 & 8.51 & 6.20 & 6.2 \\
\hline $\mathrm{Gd}$ & 7 & - & 9.81 & - & 10.8 \\
\hline $\mathrm{Tb}$ & 8 & $4.86(5.82)$ & 4.91 & - & 9.41 \\
\hline Dy & 9 & - & 6.61 & - & 8.47 \\
\hline Но & 10 & - & 7.66 & - & 8.60 \\
\hline $\operatorname{Er}$ & 11 & $7.42(7.98)$ & 7.56 & - & 8.78 \\
\hline $\operatorname{Tm}$ & 12 & $7.52(7.89)$ & 7.51 & $\approx 7.9$ & 7.92 \\
\hline $\mathrm{Yb}$ & 13 & - & 8.71 & 6.59 & 6.63 \\
\hline $\mathrm{Lu}$ & 14 & - & 10.01 & - & - \\
\hline
\end{tabular}

\section{FIGURES}

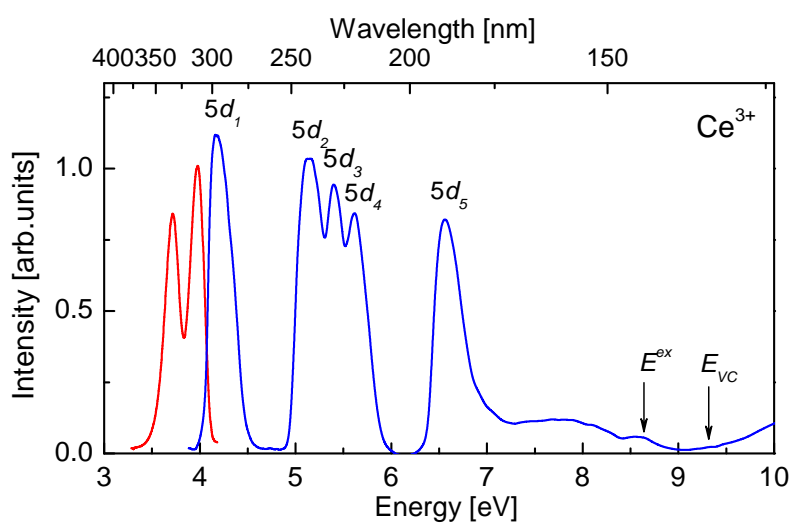

FIG. 1: The excitation spectrum of $3.71 \mathrm{eV}$ emission and the emission spectrum under $5.17 \mathrm{eV}$ excitation of $\mathrm{Ce}^{3+}$ in $\mathrm{LiYP}_{4} \mathrm{O}_{12}$ at $10 \mathrm{~K}$.

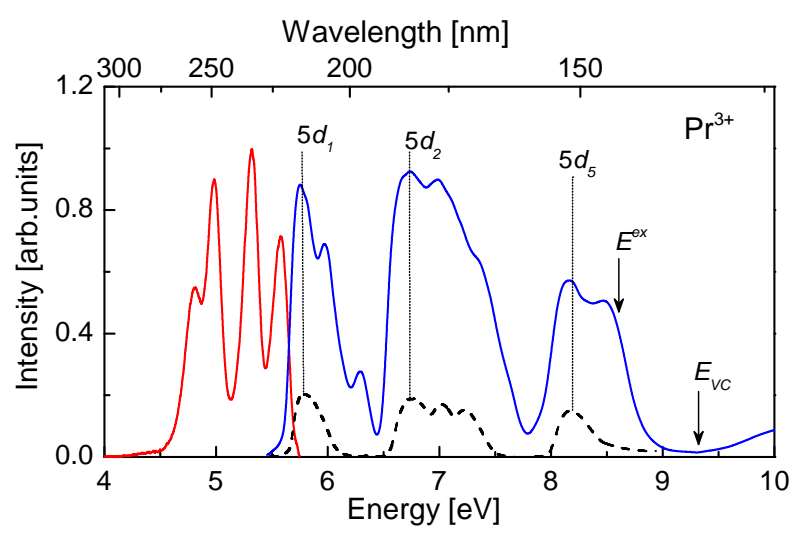

FIG. 2: The excitation spectrum of $4.96 \mathrm{eV}$ emission and the emission spectrum under $6.89 \mathrm{eV}$ excitation of $\mathrm{Pr}^{3+}$ in $\mathrm{LiYP}_{4} \mathrm{O}_{12}$ at $10 \mathrm{~K}$. The dashed curve is the excitation spectrum of $\mathrm{Ce}^{3+}$ emission shifted with $1.57 \mathrm{eV}$ to higher energy. 


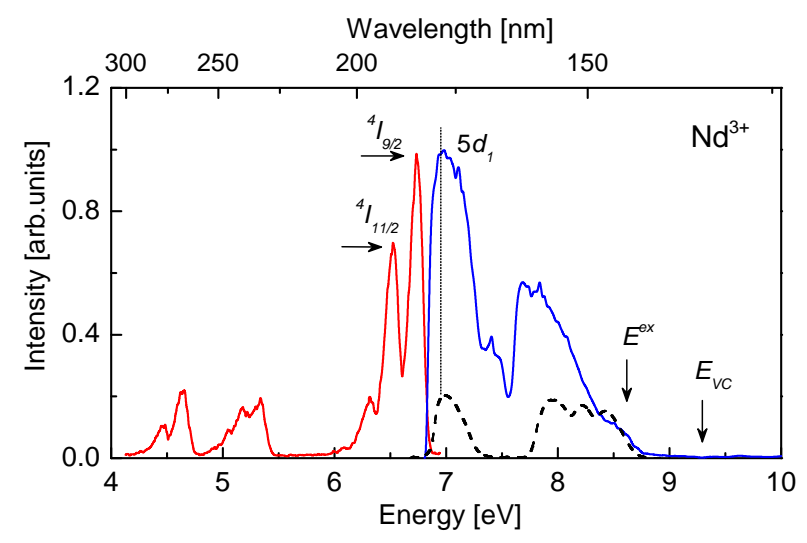

FIG. 3: The excitation spectrum of $6.49 \mathrm{eV}$ emission and the emission spectrum under $7.70 \mathrm{eV}$ excitation of $\mathrm{Nd}^{3+}$ in $\mathrm{LiYP}_{4} \mathrm{O}_{12}$ at $10 \mathrm{~K}$. The dashed curve is part of the excitation spectrum of $\mathrm{Ce}^{3+}$ emission shifted with $2.77 \mathrm{eV}$ to higher energy.

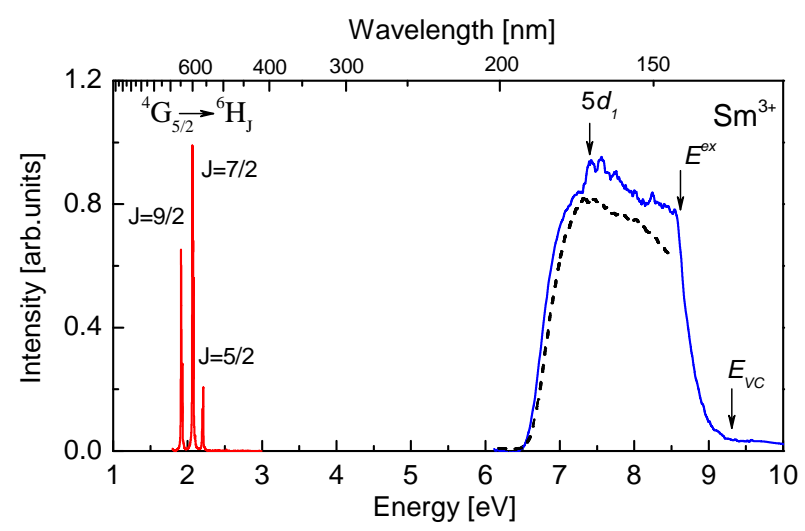

FIG. 4: The excitation spectrum of $2.07 \mathrm{eV}$ emission and the emission spectrum under $7.13 \mathrm{eV}$ excitation of $\mathrm{Sm}^{3+}$ in $\mathrm{LiYP}_{4} \mathrm{O}_{12}$ at $10 \mathrm{~K}$. The dashed curve is part of the excitation spectrum of $\mathrm{Eu}^{3+}$ emission shifted with $1.20 \mathrm{eV}$ to higher energy.

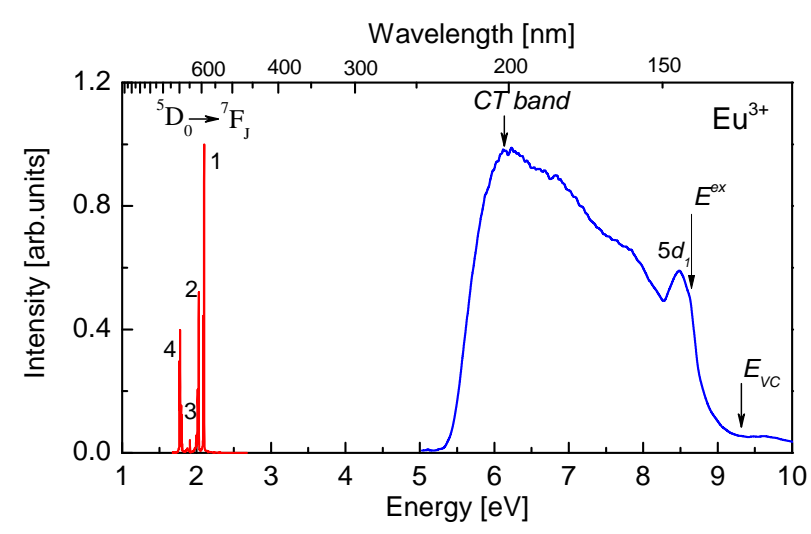

FIG. 5: The excitation spectrum of $2.11 \mathrm{eV}$ emission and the emission spectrum under $7.09 \mathrm{eV}$ excitation of $\mathrm{Eu}^{3+}$ in $\mathrm{LiYP}_{4} \mathrm{O}_{12}$ ar $10 \mathrm{~K}$. 


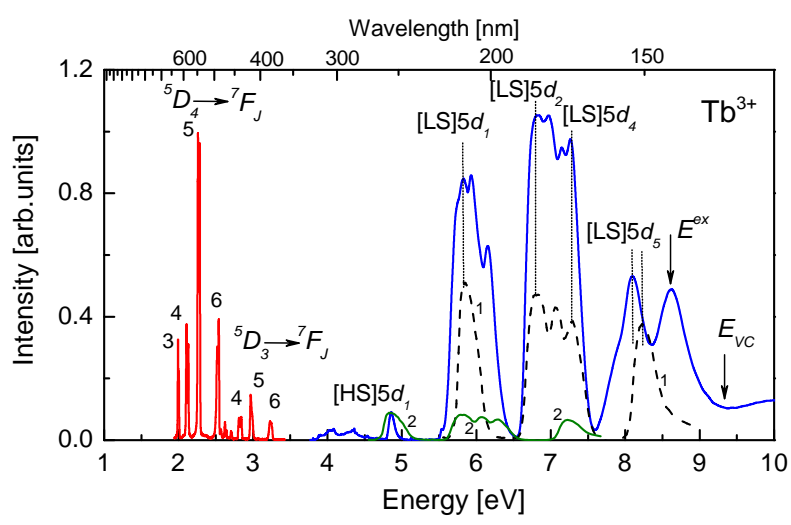

FIG. 6: The excitation spectrum of $2.27 \mathrm{eV}$ emission and the emission spectrum under $6.89 \mathrm{eV}$ excitation of $\mathrm{Tb}^{3+}$ in $\mathrm{LiYP}_{4} \mathrm{O}_{12}$ at $10 \mathrm{~K}$. The dashed curve 1) and the dotted curve 2) are relevant parts of the excitation spectrum of $\mathrm{Ce}^{3+}$ emission shifted with $1.64 \mathrm{eV}$ and 0.64 to higher energy, respectively.

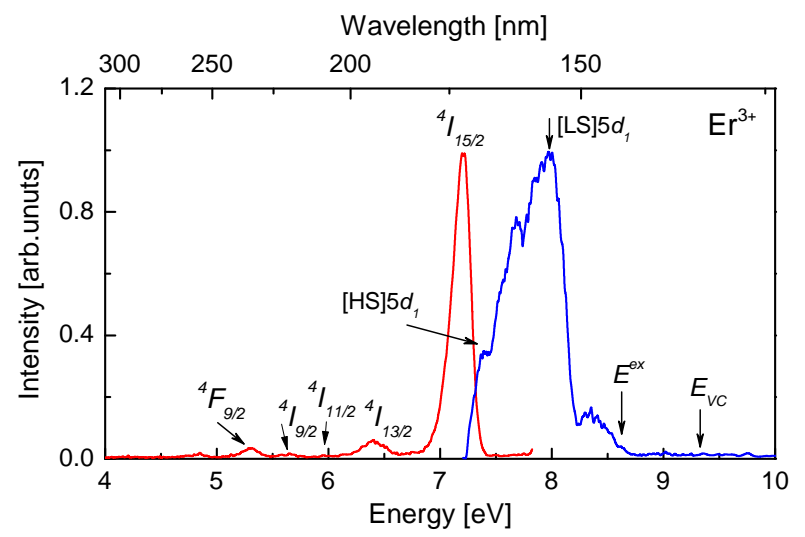

FIG. 7: The excitation spectrum of $7.13 \mathrm{eV}$ emission and the emission spectrum under $7.90 \mathrm{eV}$ excitation of $\mathrm{Er}^{3+}$ in $\mathrm{LiYP}_{4} \mathrm{O}_{12}$ at $10 \mathrm{~K}$.

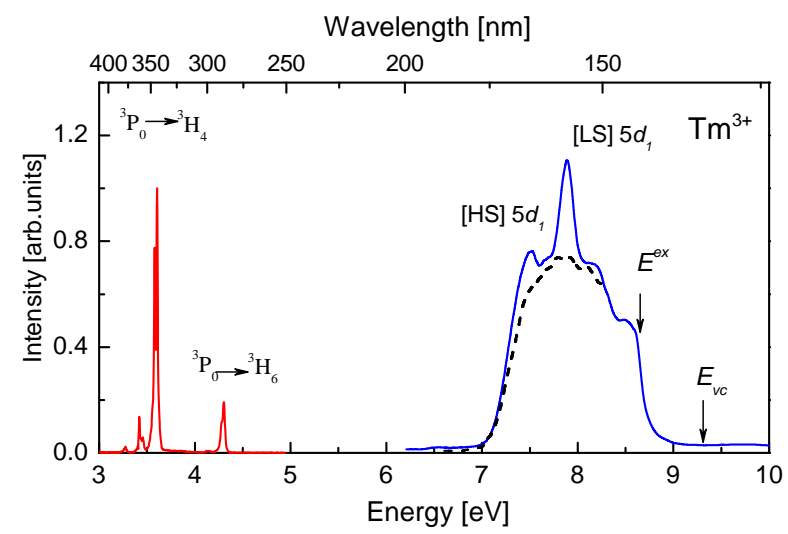

FIG. 8: The excitation spectrum of $3.60 \mathrm{eV}$ emission and the emission spectrum under $7.13 \mathrm{eV}$ excitation of $\mathrm{Tm}^{3+}$ in $\mathrm{LiYP}_{4} \mathrm{O}_{12}$ at $10 \mathrm{~K}$. The dashed curve is part of the excitation spectrum of $\mathrm{Yb}^{3+}$ emission shifted with $1.29 \mathrm{eV}$ to higher energy. 


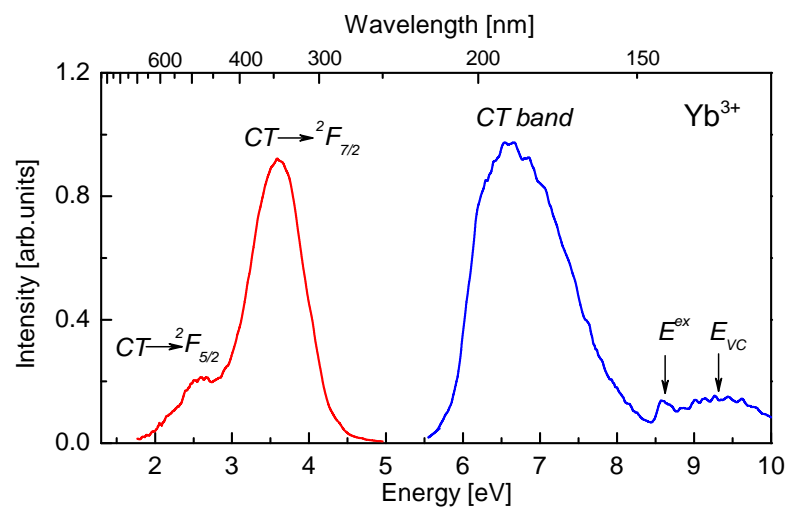

FIG. 9: The excitation spectrum of $3.75 \mathrm{eV}$ emission and the emission spectrum under $6.49 \mathrm{eV}$ excitation of $\mathrm{Yb}^{3+}$ in $\mathrm{LiYP}_{4} \mathrm{O}_{12}$ at $10 \mathrm{~K}$.

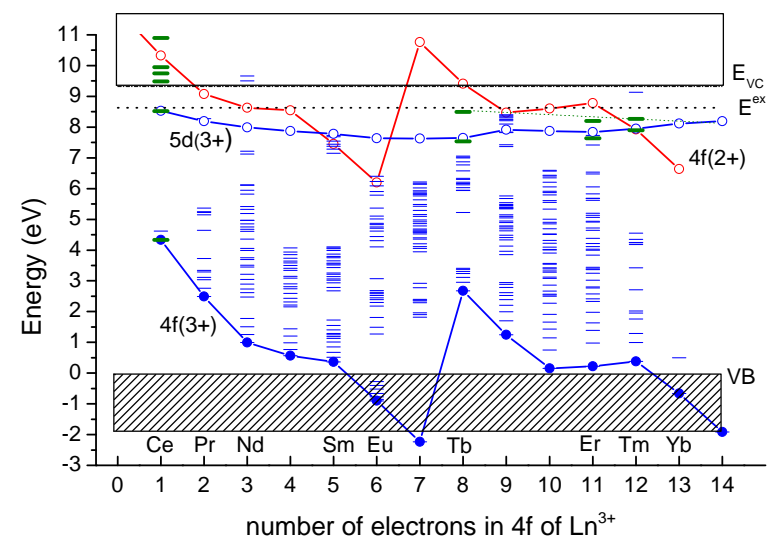

FIG. 10: Lanthanide energy levels scheme for $\mathrm{LiYP}_{4} \mathrm{O}_{12}$.

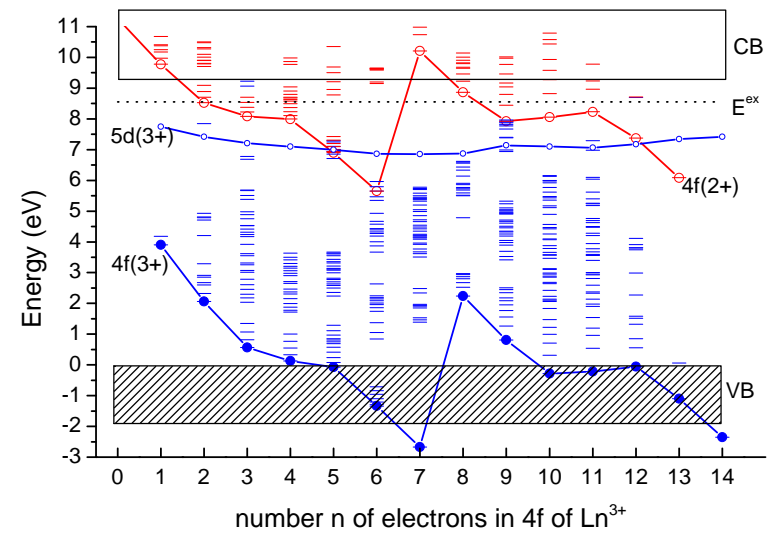

FIG. 11: Lanthanide energy levels scheme for $\mathrm{YPO}_{4}$. 


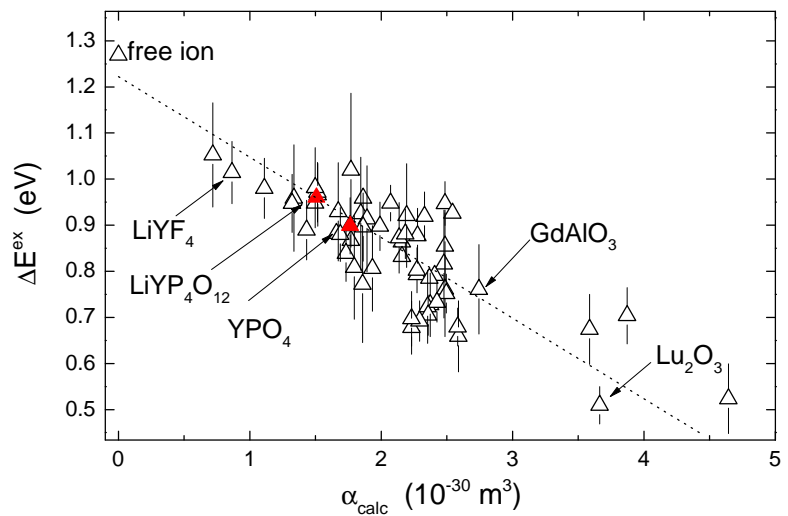

FIG. 12: Exchange splitting $\Delta E^{e x}$ between the [LS] and [HS] states of $\mathrm{Tb}^{3+}$ in compounds displayed against the calculated spectroscopic polarizability $\alpha_{\text {calc }}$ of those compounds. 